\title{
Supply chain management best practices: A case of humanitarian aid in southern Africa
}

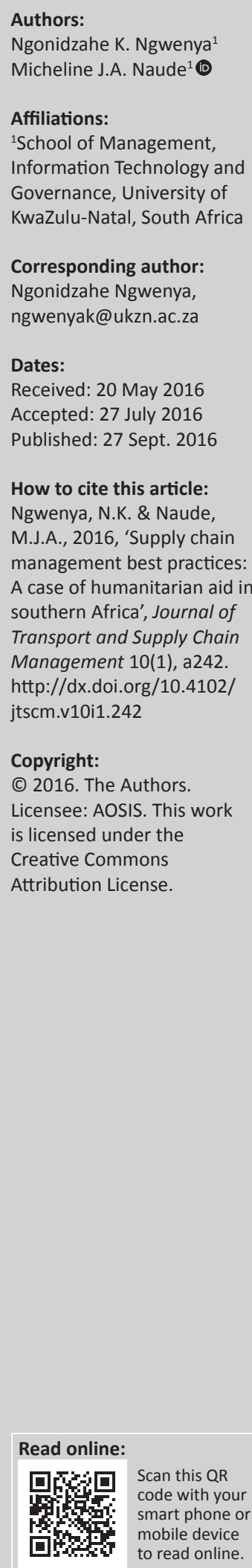

Background: A key contemporary issue in the southern African region is the increased frequency of the number of natural disaster occurrences. Because of the extent of the damage as a result of these disasters, beneficiary needs have to be met to mitigate against consequent hardships and the loss of lives in the affected communities.

Objectives: This article reports on a study that investigated supply chain management best practices that are employed by the United Nations World Food Programme's (UNWFP) when dealing with disasters.

Method: This exploratory study consisted of five in-depth interviews with voluntary participants at the UNWFP regional office in Johannesburg to determine the various initiatives adopted by the UNWFP that ensure successful disaster relief operations. Thematic analyses were used to analyse the collected data.

Results: Based on the themes generated from the in-depth interviews, supply chain best practices were mainly linked to the concepts of agility, responsiveness and flexibility.

Conclusion: The main findings revealed that the strategic planning, implementation and controlling of agile, flexible and responsive supply chain practices can contribute to the success of logistical operations supporting humanitarian efforts in southern Africa.

\section{Introduction}

Southern Africa has experienced a combination of natural disaster occurrences such as bush fires, floods, disease and epidemic outbreaks as well as droughts (McClintock 2009:297). These have resulted in the loss of lives and sustained injuries, with many affected communities displaced from their homes and thus prone to starvation and destitution (United Nations [UN] 2009).

Recently, there has been an increase in the frequency of disaster occurrences, and this has resulted in greater challenges encountered by relief organisations because they are expected to respond effectively, efficiently and timeously to the increasingly diverse natural disaster occurrences. Some of the major disasters experienced in the region include cyclone Favio, which displaced approximately 120000 households in Madagascar and Mozambique (Lukamba 2010:484), and an acute drought crisis during 2007-2008, which resulted in countries such as Malawi, Zambia and Lesotho requiring food aid for up to 3.6 million, 1.2 million and 1.1 million people respectively (IFRC 2007).

At the highest level, humanitarian supply chain management during relief operations consists of activities such as the management of stakeholders, strategic planning and assessment efforts with the intention of facilitating efficient and effective responses (Talib \& Hamid 2014:27). Initially, the relief organisations are faced with the challenge of acquiring the needed supplies from different donors. Then, at the next level, the success of the relief operation depends on the most productive supply chain management practices being put in place, relative to vital activities such as procurement, warehousing, transportation and distribution, planning and execution (Fritz Institute 2010; Tatham \& Pettit 2010:609). Consequently, the donor supplies need to be delivered to the affected sites within the shortest possible period of time (Perry 2007:410).

Successful relief operations need to ensure that the appropriate supplies are procured and transported 'in the right quantities, to the right people at the right location and at competitive prices' (Herrmann 2007:12). The benefit of achieving supply chain efficiency during humanitarian operations is the minimisation of the extent of suffering of the affected communities (Zhao, Xie \& Zhang 2002:34) and to avoid any further loss of lives. As a result, it is essential that the supply chain be agile, flexible and responsive. 
Within the above context, the focus of this article is to provide an overview of how the United Nations World Food Programme (UNWFP) has made significant strides in successfully responding to natural disaster operations in southern Africa.

This article comprises four sections. The first section is the introduction, including the background and the literature review. The second section presents the research methodology utilised for the research, and the third section presents an explanation and analysis of the findings. Lastly, the fourth section concludes with a conclusion.

\section{Literature review}

\section{Context of humanitarian supply chains}

Humanitarian supply chains consist of a network of interaction between donor governments, international and locally based agencies, suppliers and numerous other stakeholders that co-ordinate the flow of supplies, services, finances and information for the purposes of responding to beneficiary needs (Howden 2009:5). The movement of supplies and materials should be cost-effective and therefore proper planning and control are essential (Herrmann 2007:12). Humanitarian logistics involve a set of supply chain activities carried out during disaster operations with the aim of attaining co-ordinated logistics excellence. These activities involve the task of transporting large volumes of supplies and materials that are essential during relief operations (Tatham \& Pettit 2010:611; Thomas \& Kopczak 2005:3; Tomasini \& Wassenhove 2004:438). It is necessary that all the humanitarian events occurring before and after a disaster are appropriately conducted in order to meet the needs of the affected communities. This can be achieved when the factors influencing relief operations are taken into account during such operations (Minnich \& Maier 2005:34). Table 1 presents some of the main disaster occurrences common in southern Africa and the beneficiary needs.

\section{Factors to be considered in designing humanitarian supply chain frameworks}

Humanitarian organisations face various challenges during relief operations. These challenges need to be identified in order for the ideal supply chain best practices to be implemented. Pateman, Hughes and Cahoon (2013:90) identified a number of the dominating challenges including the unpredictability of occurrences with respect to timing, geographic location and magnitude.
Two key issues have been identified to impact on the success of any supply chain - both are closely linked. Those are the flow of accurate information and effective and accurate demand management.

The flow of accurate information within any supply chain is a critical factor and influences response efficiency (Pettit \& Beresford 2009:458) as does accurate demand chain management, which governs the success of the operation and covers a set of practices with the goal of managing the entire demand chain from the end customer and working backwards to the suppliers raw materials (Heizer \& Render 2014:339). The initial period after a natural disaster occurrence is characterised by a sense of panic with the communities usually having inadequate resources available to initiate appropriate and correct response operations. As they usually occur without prior warning, there is no time to conduct needs assessments (Tatham \& Spens 2011:17), which leads to difficulties in accurately determining the number of affected people, their geographic location and type of and number of relief supplies required.

With the affected governments and relief organisations not being in a position to appropriately assess the damages (Balcik et al. 2010:28) and with little or no demand information available, the respondents usually transfer supplies to the affected areas with the hope that such supplies will be adequate to meet the needs of those affected by the disaster (Kovacs \& Spens 2007:104). This often leads to a congestion of the supply chain with unwanted and inappropriate supplies, as donors and relief organisations respond by transferring supplies into the supply chain, without having accurately determined the actual beneficiary needs (Murray 2005:3).

Humanitarian operations are often conducted in areas with destabilised infrastructure, including improper transportation channels, such as airports, road networks and railway lines (Kovacs \& Spens 2007:100). These conditions affect the success of disaster operations exacerbating the accessibility of the affected areas. The majority of humanitarian disaster operations are usually under-funded, which results in most organisations not prioritising the adoption of key supply chain concepts. This affects and compromises the success of their disaster operation efforts (Moe \& Pathranarakul 2006:400).

Another key variable in disaster relief operations is the availability of supplies. This includes supplies of sanitary medical products, foodstuffs and water plus clothing and shelter equipment, all of which need to be procured and

TABLE 1: Main disaster occurrences and the corresponding beneficiary needs.

\begin{tabular}{llll}
\hline Disaster classification & Disaster occurrence & Main characteristics & Beneficiary needs \\
\hline $\begin{array}{l}\text { Hydro-meteorological } \\
\text { disasters }\end{array}$ & $\begin{array}{l}\text { Flooding, cyclones and } \\
\text { flash floods }\end{array}$ & $\begin{array}{l}\text { Massive torrential rains. } \\
\text { Displaces households. } \\
\text { Destroys infrastructure and communication networks. } \\
\text { Limited access and movement between areas. }\end{array}$ & $\begin{array}{l}\text { Relocation to unaffected areas. } \\
\text { Provision of temporary shelter, clothing and sleeping material. } \\
\text { Provision of food supplies and clean drinking water. }\end{array}$ \\
& $\begin{array}{l}\text { Droughts and } \\
\text { widespread starvation }\end{array}$ & $\begin{array}{l}\text { Acute food shortages triggered by a decline in cereal and } \\
\text { crop production. } \\
\text { More communities requiring food aid. } \\
\text { Children are usually the most vulnerable group. }\end{array}$ & $\begin{array}{l}\text { Transportation of food supplies to the affected communities. } \\
\text { Main food supplies on demand - grains, cereals, tinned foods and } \\
\text { high-energy biscuits. } \\
\text { Implementation of measures aimed at improving food sustainability. }\end{array}$ \\
Biological disasters & Epidemic outbreaks & $\begin{array}{l}\text { Outbreaks of diseases such as cholera, typhoid and malaria. } \\
\text { Need to be properly managed. } \\
\text { Affected individuals need medical and food supplies. }\end{array}$ & $\begin{array}{l}\text { Provion of medical care and supplies to affected areas. } \\
\text { Implemtation of measures to prevent the diseases from spreading. } \\
\text { Provision of consistent medical and food supplies. }\end{array}$ \\
\hline
\end{tabular}


distributed during operations (Patemen et al. 2013:93). Chakravarty (2010:3) indicates that natural disaster occurrences are characterised by a drastic increase in demand for supplies required by the affected population who are dependent on relief aid. This implies that organisations have to identify a credible pool of suppliers to cope with the increasing level of demand. The required set of supplies may vary greatly depending on the nature, type and impact of the disaster occurrence and the demographics, as well as social and economic conditions of the affected areas. In addition, as experienced by the UNWFP during the southern Africa droughts in the year 2000, supply patterns are further complicated by the increasing costs of relief supplies where the prices of grain and wheat have increased substantially because of the adverse conditions (WFP 2011).

Lead time refers to the total time required for an ordered product to be delivered (Heizer \& Render 2014:524). Lead time is commonly used as a measure of efficiency with most customers preferring that the period between placing an order and receiving it be kept at an absolute minimum. Because of the unexpected and extraordinary nature of the disaster event, relief organisations require supplies to be delivered from either their donors or suppliers within the least possible time (Chopra \& Meindl 2013:328) in order to alleviate the hardship of the people affected by the disaster. A key expectation from relief organisations is to source their supplies on a shorter lead time basis (Sheu 2006:687).

\section{Supply chain management practices applicable during humanitarian relief operations}

Considering the challenges explained above that are encountered during humanitarian disaster operations, it is necessary that a framework of supply chain practices is identified and adopted that will ensure that disaster operations are conducted effectively and efficiently. Concepts addressing agility, flexibility and responsiveness have been identified as relevant as they place an emphasis on customer focus (Aprile, Garavelli \& Giannoccaro 2005:25; Stevenson \& Spring 2007:685). Researchers acknowledge the significance of these concepts as they enhance the level to which an organisation adapts to changing customer needs. Key to achieving agility is the use of the supply chain concept of postponement, with access to virtual integration capability and through the effective co-ordination of all activities.

Agility is defined as the ability of an organisation to copy and remain successful in an unpredictable and continuously changing market environment. This implies the organisation's supply chain is capable of absorbing and containing any arising uncertainties (Ismail \& Sharifi 2006:43). Vonderembse et al. (2006:99) are of the view that agile supply chains enable organisations to rapidly respond to a changing, dynamic and highly uncertain environment by being context specific. This is particularly relevant in disaster relief operations.

Postponement is a supply chain management concept where activities are only performed when specific customer orders are received. It is a concept that is closely associated with agility and is usually implemented by organisations operating in conditions of uncertainty and is considered a building block towards achieving customer responsiveness (Charles, Lauras \& Wassenhove 2010:725). Postponement as an agility tool is mostly implemented during inventory management processes, whereby humanitarian organisations hold stocks for specific generic products that are later customised as determined by the needs of the affected communities (SimchiLevi, Kaminsky \& Simchi-Levi 2008:218).

Virtual integration is responsible for ensuring that the organisation has the ability to implement improved process control measures and is also able to manage demand volatility. It is a common strategy, key in achieving agility and used in supply chains to reduce environmental uncertainty through emphasising interorganisational co-ordination, information processing and control (Wang, Tai \& Wei 2006:46). For supply chains to be considered agile and responsive, there is a need for the implementation of IT systems to facilitate common operations between response stakeholders such as purchasing, logistics and distribution. Virtual structures are dynamic and ensure that there is improved speed and flexibility through building a united information space with extensive and accurate communication services (Camarinha-Matos \& Afsarmanesh 2004:12).

Moeiny and Mokhlesi (2004:8) define coordination as involving an atmosphere in which all humanitarian relief organisations and their stakeholders willingly share information that is key during relief operations. Co-ordination measures ensure that all the organisations and parties that are involved during disaster management make informed decisions based on information provided by suppliers, donor community and their partners. When numerous partners are involved in analysing the needs of the beneficiaries, there is usually an accurate reflection of the exact needs, while a number of the information that is freely exchanged involves beneficiary preferences and demand levels (Oloruntoba 2007:3).

Supply chain flexibility, is described as affecting specific organisational components such as the product mix and volume and is defined in terms of mobility, uniformity and range, referring to the different states in which a system can adopt and be able to switch efficiently from making one product to another (Jangga et al. 2015:265). This implies that the organisation is able to deliver and assemble a diversity of products within a specified range (Stevenson \& Spring 2007:687). Although the concept of flexibility is derived from manufacturing organisations, efforts have been made to implement this principle in service and humanitarian organisations (Krajewski, Wei \& Tang 2005:460).

The aim of agility and flexibility is to improve the responsiveness of the organisation in fulfilling the needs of its customers. The framework of agile, responsive and flexible supply chains is suitable for implementation in an environment that is characterised by rapidly changing customer demands (Chandra \& Grabis 2009:12). The main challenges faced during disaster operations involve a combination of factors, 
linked to the unpredictability of disaster occurrences in terms of time, nature and scope (Bean et al. 2011:40). Despite these, the main objective of humanitarian organisations is to respond timeously to any disaster occurrences which can be achieved through different agile, flexible and responsive initiatives (Christopher \& Towill 2001:550).

Humanitarian organisations can draw practical lessons from prior research on the concept of agility in relation to how it has been implemented in different organisational operations. As a result, an explanation of how agility has been implemented through postponement, virtualisation and coordination is appropriate.

\section{Research methodology}

A case study approach for this article was deemed appropriate as the aim was to identify the selected supply chain management practices that can be implemented during relief operations in southern Africa. Case study research is descriptive and exploratory and is defined as an approach to research that enhances the exploration of a set of variables within a specific context using a variety of data sources (Baxter \& Jack 2008:544). Malhotra (2004:77) remarks the use of this technique as common with exploratory studies where the main focus is on gaining insight into a specific subject and especially on research problems where fewer studies have been conducted (Malhotra 2004:77). However, Malhotra (2007:82) writes that causal links in case study research are difficult to test and generalisations cannot be made from single case studies.

A non-probability convenience purposive sample was used and five participants at the UNWFP southern African regional office in Johannesburg were interviewed during this study (see Table 2).

Data were gathered through in-depth interviews using a semi-structured interview guide. The interview guide included both closed and open-ended questions and was flexible enough to allow the interviewer to be able to adjust the sequence in which questions were asked and to further probe the participants based on their responses.

In order to ensure reliability during the data collection process, after having obtained permission from the participants,

TABLE 2: Profiles of the participants.

\begin{tabular}{ll}
\hline Characteristics & Description \\
\hline Gender & $\begin{array}{l}\text { A total of five participants were involved during this research } \\
\text { study, of which four were male and one was female. }\end{array}$ \\
Qualifications & $\begin{array}{l}\text { Most of the participants have different university qualifications } \\
\text { in the Engineering, Project Management and Supply Chain } \\
\text { Management disciplines. They all have an average of } 5 \text { years } \\
\text { work experience in the humanitarian environment. }\end{array}$ \\
Job title & $\begin{array}{l}\text { The job titles held by the participants at the UNWFP include } \\
\text { Regional Logistics Officer, Procurement and Logistics Specialist } \\
\text { and Logistics Planner. }\end{array}$ \\
Years with the & $\begin{array}{l}\text { The participants have been involved in many operations with } \\
\text { the UNWFP and they have an average of 10 years each with } \\
\text { the organisation. In those 10 years, an average of 7 years were } \\
\text { involved in relief operations within southern Africa and the } \\
\text { other 3 years to operations outside of the region. }\end{array}$ \\
\hline UNWFP, United Nations World Food Programme.
\end{tabular}

UNWFP, United Nations World Food Programme. interviews were recorded using a digital voice recorder and these recordings were later transcribed verbatim and checked against voice recordings for accuracy. The results generated from the interviews were analysed using the thematic data analysis approach. Thematic analysis is a general approach to analysing qualitative data. It involves identifying themes and patterns within the data (Wagner, Kawulich \& Garner 2012:231). Once the recordings were transcribed, the data were unitised and categorised according to the study themes, and any data identified outside of the themes were discarded. The process involved the identification of themes through careful reading and re-reading of the data. This is a form of pattern recognition within the data, where emerging themes become the categories for analysis and allowed for the identification of supply chain management best practices patterns, such as agility, flexibility and responsiveness. Based on the results generated, the data were displayed in the form of a thematic map.

\section{Results and discussion of findings}

In order to identify the benefits associated with the implementation of supply chain management best practices during natural disaster operations, participants were asked to list and explain the various initiatives adopted by the UNWFP that aim to make sure that disaster relief operations are successful. Based on the themes generated from the indepth interviews, supply chain best practices were mainly linked to the concepts of agility, responsiveness and flexibility. Figure 1 provides a thematic map outlining a summary of the different supply chain practices implemented by the UNWFP and what they aim to achieve during relief operations.

The results have been organised into different qualitative themes that are further explained using the categories below.

\section{Theme 1: The adoption of flexible supply chain management practices}

The level of complexity of humanitarian relief operations implies that the adoption of flexible supply chain practices is essential to ensure that organisations effectively respond to a variety of relief occurrences (Tomasini \& Van Wassenhove 2009:550). For the

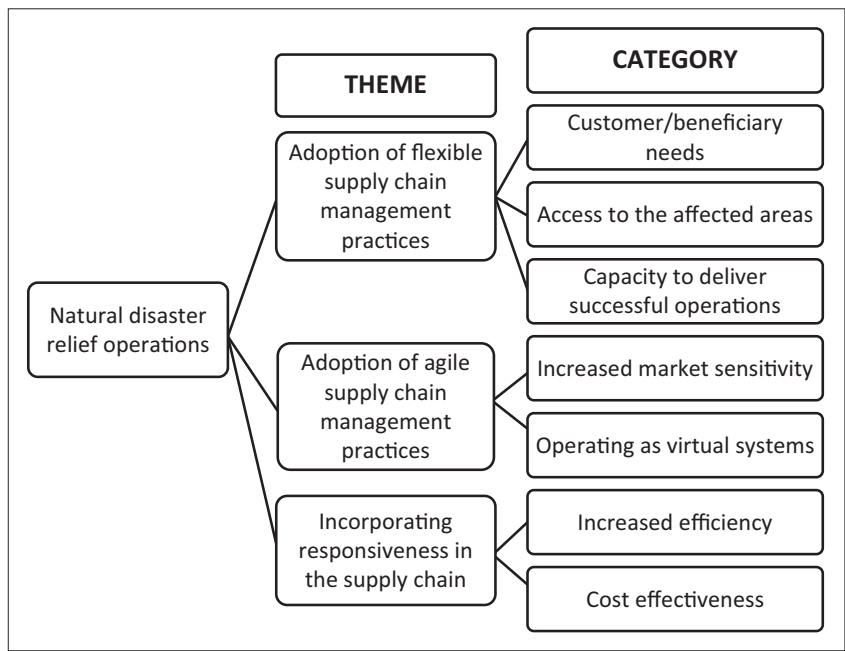

FIGURE 1: Thematic map (supply chain management practices). 
UNWFP, adaptation in these different conditions is attained through ensuring that flexible supply chain practices are adopted. The organisation has honoured the firm commitments it has made by being engaged in fragile environments despite the challenging circumstances it encounters.

The range of flexible supply chain management practices that the organisation has adopted encompasses its policies pertaining to how it manages partnerships created with other stakeholders and the infrastructure it has invested in. The benefits of adopting flexible supply chain practices are further explained in the following categories.

\section{Category 1: Customer or beneficiary needs}

Fulfilling the needs of the affected communities is the core objective of the UNWFP, which is achieved through the implementation of flexible supply chain practices. The focus of the UNWFP is on delivering food supplies and other related disaster needs to the communities at the appropriate time and ensuring that there are sufficient staff and materials available to distribute to the affected areas.

Examples provided by the participants represent a useful indication of the efforts made by the UNWFP towards improving customer or beneficiary responsiveness. The UNWFP considers all its beneficiaries as its main target customers. Thus, all efforts and attempts are directed towards fulfilling their required needs. For example, in 2012 the UNWFP distributed an estimated 230862 metric-tonnes of food to 5347786 million beneficiaries.

The following is one of the verbatim quotes extracted from the various participants, which supports that disaster operations conducted by the organisation are sensitive to customer' needs:

As an organisation we have adopted a beneficiary focused approach, which is driven by being sensitive to all the needs of the communities that we are involved in. One of the key policies that we used during the Zambia food crisis (drought) involved 'cash and vouchers'. (Participant 1, Male, Regional Logistics Officer)

The cash vouchers are mainly used in areas that are hard hit by food shortages (droughts). Cash vouchers are a substitution for the traditional ways of providing food and are more flexible.

The UNWFP is responsive to the needs of its intended beneficiaries through its strategic policies, which includes improved efforts to assess the needs of the affected communities and improved emergency communications. Efforts continue to be made to ensure that all the natural disaster occurrences experienced in the region are properly managed through carrying out proper assessments and information management in order to understand the needs of the beneficiaries and thereby promptly address them.

\section{Category 2: Access to the affected areas}

Most disaster occurrences cause infrastructural damage, such as the disruption of railway systems, bridges, roads, public dwellings and port systems. This means that the UNWFP struggles to find safe passages to provide aid through distributing relief supplies to the affected areas. The organisation, with an advanced transportation and logistics network in place, enables it to be more flexible in accessing different areas affected by various natural disaster occurrences.

The successes have been attained as a result of the implementation of measures such as the use of the United Nations Humanitarian Air Services (UNHAS) and the Rapid Response Mechanism. These successes have improved the UNWFP's ability to access various areas. Within this context, the following are a selection of quotes from the participants:

... the UNHAS programme has allowed UNWFP provision for access into important priority destinations enabling humanitarian staff to begin the work of assessing needs and initiating timely response operations. (Participant 3, Male, Logistics Planner)

Accessibility by the UNWFP is mainly achieved through a diversified pool of transportation infrastructure, which enables it to access the different areas in which a natural disaster occurs. Other determinants of access to affected areas include the ability of the organisation to identify the affected areas through effective information management and the collaborative efforts offered by the other partners through the Cluster Approach. These have a positive contribution towards ensuring that the flexible approaches implemented enhance the organisation's access to all the affected areas.

\section{Category 3: Capacity to deliver successful operations}

As a result of adopting flexible supply chain management practices, the UNWFP is able to handle disaster operations of varying capacities. The participants described capacity as 'the ability of the organisation to conduct operations of different volumes, in various areas, at different times and to provide a diverse range of services and relief supplies' (Participant 1, Male, Regional Logistics Officer). This ability is mainly influenced by the increased presence of the organisation through its regional centres. In southern Africa, the regional office is in Johannesburg, with different country offices spread out throughout the region. These offices usually take charge in responding to disaster occurrences within their boundaries and, if need be, other regional and international offices may assist.

Capacity building is one of the main core competencies that the UNWFP has achieved over time through various tools. On participant quoted:

Our mandate as an organisation lies in supporting natural disaster prevention, preparedness and response to vulnerable communities. We have therefore developed distinct comparative advantages in areas involving analysis, capacity development and operational capacity to strong inter-agency leadership. (Participant 2, Female, Logistics Officer)

Based on this quote, it can be inferred that the organisations' logistics capacity is designed to be able to adapt to the various levels of demand resulting from the different disaster occurrences. 


\section{Theme 2: The adoption of agile supply chain management practices}

The emphasis of the UNWFP is in ensuring that it has the ability to adapt to the changing response conditions because it is involved in conducting various disaster operations in different locations. Based on this theme, the insights are provided on how the organisation has implemented agile supply chain practices and how these practices enabled successful disaster operations.

\section{Category 1: Increased market sensitivity}

Market sensitivity implies that the UNWFP is able to initiate disaster operations in any location and at any given time. The ability with which the organisation is able to initiate disaster operations is dependent on factors such as the availability of funds, donors to support operations and other initiatives that enable UNWFP to respond to the increasing needs of the affected communities.

The organisation, in spite of the instability of the donor community, ensures that funds are available to support any emerging disaster occurrence. Their efforts include forging partnerships with the corporate and public sector, who are usually the first to respond when a disaster occurs. For example, during the 2014 floods in Mozambique, the government of the Republic of South Africa was one of the first donors to pledge funds and provide military infrastructure and personnel. One of the participants indicated how consistent streams of funds and donor contributions enhance agility within the organisation's supply chain:

The erratic weather patterns that resulted in drought occurrences in Malawi, Zambia and Zimbabwe in 2012 resulted in the Department of Agriculture (South Africa) providing monetary aid to the UNWFP. The terms attached to this fund ensured that supplies should only be procured from small holder farmers registered with the Department. (Participant 1, Male, Regional Logistics Officer)

The funding element is mainly a contributor to the practices that the organisation implements to ensure that disaster operations are conducted successfully, despite the uncertain and dynamic humanitarian conditions. Some of the important initiatives highlighted include:

- The pre-positioning of supplies.

- The pre-positioning of supplies effectively reduces risk in anticipation. Generally, the UNWFP has invested in efforts to ensure that there are different hubs, which it manages. These are designed to facilitate action in response operations that may present various challenges.

\section{A sensitivity needs assessment mechanism}

The aim of a sensitivity needs assessment mechanism is to ensure that a proper assessment of the disaster needs is efficiently carried out so that relevant aid is provided to the affected communities. The UNWFP has an assessment team trained and equipped to identify the needs arising after any disaster occurrence. This is aimed at ensuring that the right information pertaining to a disaster is accessed before planning relief operations suitable for the affected area.

\section{Category 2: Operating as virtual systems}

The UNWFP has invested in virtual systems in an attempt to promote and facilitate the effective movement and management of information. The information provides accurate insight into the accessibility, terrain of the affected area and the extent of the damage. This also ensures that the organisation is able to track all the information that may be of benefit during disaster operations. The UNWFP has partnered with GT Nexus for Logistics Visibility and Supply Network Agility to develop their information sharing systems.

Most of the participants indicated that supply chain agility is one of the most important pillars that determine the success of the UNWFP and this has effectively been achieved through the design of proper management of networks:

The UNWFP operates a global supply chain that needs to be highly agile, meaning that there needs to be an ability to deliver the right supplies to the affected areas, the visibility of the cargo and movement of deliveries is the main variable to running an agile network. (Participant 3, Male, Logistics Planner)

Some of the services provided by the system include constant updates on the status of the various shipments and the provision of relevant information to the different stakeholders involved in a disaster operation.

\section{Theme 3: Incorporating responsiveness into the supply chain}

This theme provides insight into the diverse advantages that are incurred by the organisation as a result of implementing responsive supply chain practices. The main categories that are identified in this theme describe (1) increased efficiency and (2) cost-effectiveness. The participants provided insight into how the disaster operations performed by the organisation to date achieved a desirable level of efficiency and cost-effectiveness.

\section{Category 1: Increased efficiency}

The efforts of the organisation in its supply chain focuses on ensuring increased efficiency during disaster operations. During disaster operations, every minute is vital when it comes to reaching out to the most vulnerable and providing them with essential food supplies:

\footnotetext{
... In ensuring that the UNWFP is responsive to natural disaster occurrences, we have made strategic and critical investments in infrastructure and technology which has encouraged innovation across the organisation and has been a visible means towards fostering efficiency. (Participant 4, Male, Regional Procurement Specialist)
}

The findings indicate that UNWFP considers efficiency as being the economic measure of how inputs and resources are converted into results. In other words, it illustrates how UNWFP is able to make use of diverse infrastructural resources and employee capability to deliver fast and timely response operations. In enhancing its ability to be responsive, some of the activities it has focused on include preparedness and forward planning in procurement, shipping, transportation, distribution and programme implementation. Some of 


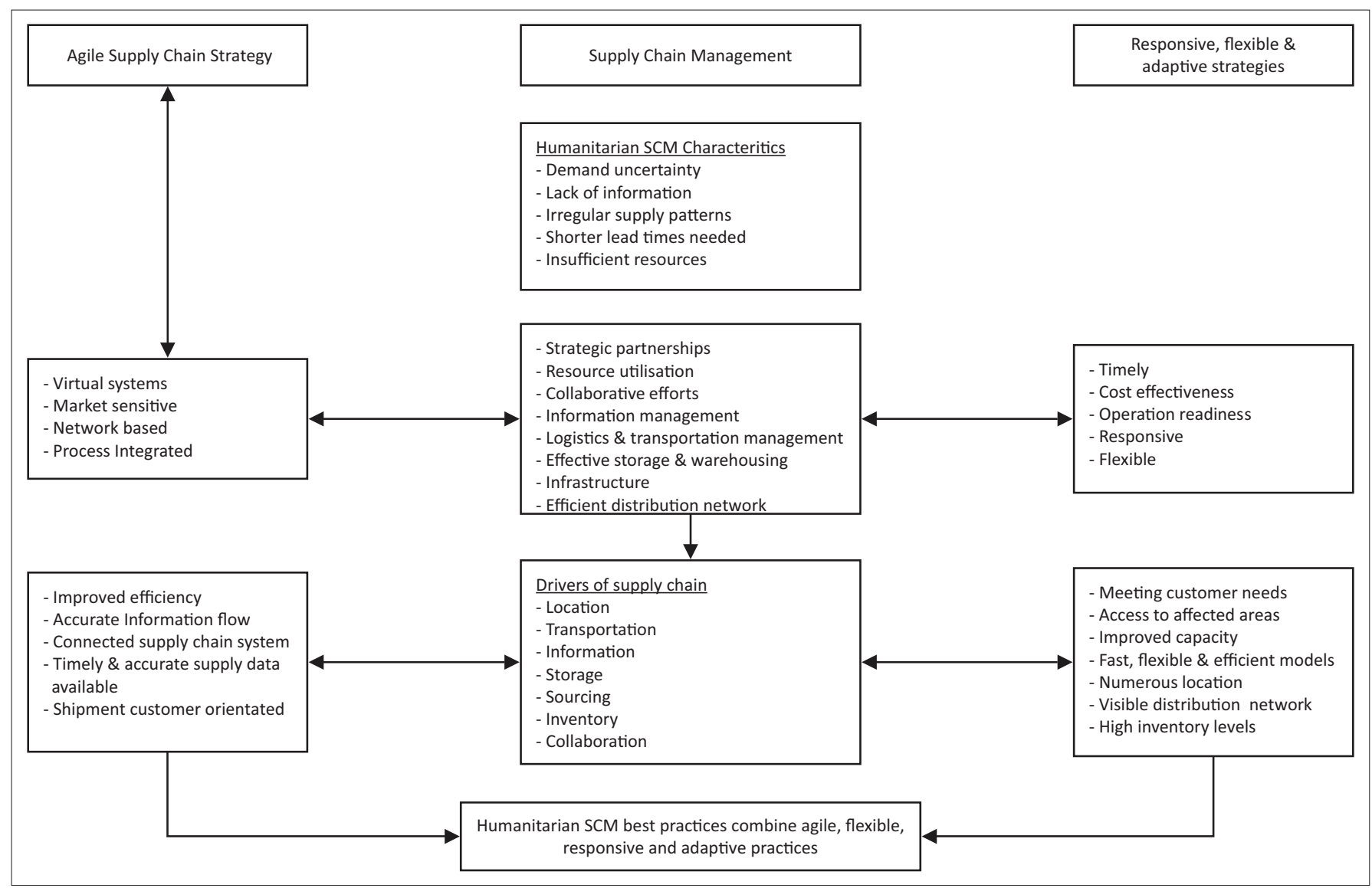

FIGURE 2: Framework of supply chain management best practices and strategies.

the critical strategies facilitating responsiveness can be derived from the statement below:

\begin{abstract}
... Increased access to relief personnel and supplies is very important when faced with a sudden disaster occurrence. The UNWFP's ability to efficiently respond to the growing disaster occurrences has been facilitated by the rapid response that is offered by the standby partners, humanitarian relief depots and the forward positioning of supplies. (Participant 2, Female, Logistics Officer)
\end{abstract}

\section{Category 2: Cost-effectiveness}

It was found that UNWFP, through the implementation of different supply chain management tools, has achieved increased cost-effectiveness. Although some of the participants openly discussed how the UNWFP has been able to achieve these cost benefits, this category presents cost as a critical advantage that has been improved by responsive supply chain practices:

Our organisation remains at the forefront in terms of delivering cost-effective humanitarian assistance and continues to contribute to greater efficiency throughout the UN system. (Participant 1, Male, Regional Logistics Officer)

The participants all agreed that cost is a key determinant during disaster operations. Because of insufficient funds being available to support operations, emphasis is directed towards increased cost savings, which ensures that all funds are put into proper use.

For example, cost efficiency has been incorporated into UNWFP's procurement activities, such as the use of import parity, as explained by one of the participants:

\begin{abstract}
... The import parity approach is aimed at ensuring that there is the efficient comparison of the local and international sourcing, delivery costs and lead times involved. Based on this comparison the organisation determines the best alternative, in cases where time is not an overriding issue, the lowest cost is chosen. (Participant 4, Male, Regional Procurement Specialist)
\end{abstract}

It was found that there are other supply chain responsive practices, such as logistics and transportation-related initiatives, implemented by the UNWFP. These initiatives result in the achievement of significant cost savings and effectiveness. For example, through the Global Vehicle Leasing Programme, the organisation is able to reduce the vehicle procurement bill for the individual country offices. Through this, UNWFP is able to improve its response capability by increasing the number of vehicles available to assist during disaster operations. The vehicles are procured centrally by the UNWFP's international office and leased to the different country offices.

\section{Summary of the findings}

The research findings clarify the main benefits associated with the adoption of supply chain management best practices for implementation during natural disaster operations. Essentially, the main findings focused on what these concepts involve and what effects they have on the entire supply chain. A number of the advantages are illustrated in Figure 2, which offers a summary of the advantages associated with adopting agile, flexible and responsive supply chains during relief operations. 
TABLE 3: Recommendations for supply chain best practices.

\begin{tabular}{ll}
\hline Supply chain variable & Visible gaps \\
\hline Procurement & Failure to get supplies at the right time, price and quantities \\
& given the pool of available suppliers. \\
& $\begin{array}{l}\text { Procurement should be transparent, accountable, efficient and } \\
\text { cost-effective. }\end{array}$
\end{tabular}

\section{Recommendations}

Establish alliances with key suppliers, in order to improve negotiating power and engage in collaborative strategic sourcing.

Focus on Total Cost of Ownership for all the materials that organisations procure from various suppliers.

Optimise sourcing processes such as negotiation planning.

Maintain long-term agreements with potential suppliers in order to improve the supply capacity needed during disaster occurrences.

Maintain an updated database of suppliers that have been evaluated and qualified, in order to avoid going through the procurement process in the event of a disaster occurrence.

There are underlying challenges regarding the transportation of personnel, infrastructure and the timely distribution of supplies to the affected areas.

Humanitarian organisations incur high costs in performing logistics and transportation costs, which is usually taxing considering the availability of funding.

\section{Information management \\ Timely and accurately determining the needs of affected communities. \\ Lack of visibility between the supply chain partners. \\ Communication breakdowns during relief operations particularly during severe disaster operations. \\ Supply chain networks need to be properly structured in order to be optimised.}

Existing networks lack efficiency. They are costly to manage and deliveries are delayed, which negatively impacts efficient responsiveness.
Humanitarian organisations could explore the opportunities of using both in-house and outsourced transportation facilities.

Use of technology to improve transportation performance would include real-time tracking. This would allow carriers to identify the precise location and contents of their fleet.

Organisations could evaluate the strengths and weaknesses associated with the different modes of transportation to different areas. This could enhance their decision making.

Consider the use of transportation consultants in determining the effectiveness of current rates and carriers. This could result in humanitarian organisations negotiating best rates and carriers.

Establish an information exchange infrastructure that should be properly utilised and managed by active humanitarian organisations.

Implement improved and tested Information and Communications Technology systems for information exchange and decision support across all humanitarian organisations, for example Disaster Resource Network and Relief Web.

Develop a common database that could be utilised by the humanitarian community in southern Africa to assist in organising disaster operations.

Identify strategic locations for storage and warehousing facilities to effectively supply southern Africa. These could be managed and operated by different organisations using a cost-sharing technique.

Flexibility and uncertainty could be incorporated into the transportation networks.

Utilise some of the channels implemented by commercial organisations. This could include partnering with three Party Logistics Providers. Other humanitarian organisations could consider learning from how United Nations World Food Programme partners with organisations such as TNT and DHL.

Humanitarian organisations could use Collaborative Planning and Forecasting tools, as this could assist in facilitating demand planning through using shared data.

Implement joint capacity and demand planning.

Incorporate partnerships with the military and government as these are able to provide specialised capabilities.

TNT, Track \& Trace; DHL, Dalsey, Hillblom and Lynn (founders of DHL Worldwide Express).

\section{Recommendations}

Insight has been provided into some of the main best of the main practices used by the UNWFP. In order for humanitarian supply chains to improve their performance and to successfully respond to disaster operations, it suggested that they could improve on their procurement, logistics and transportation, collaborative efforts, information management and distribution networks.

The following suggestions that could be adopted by UNWFP and other humanitarian organisations active in southern Africa are recommended in Table 3.

\section{Conclusion}

There is an increased frequency in the occurrences of natural disasters in the southern Africa region, resulting in an increased number of disaster operations by humanitarian organisations (Lukamba 2010:484). The consequences of these occurrences vary from increased levels of suffering of the affected communities to loss of lives. Within this context, humanitarian organisations need to improve their supply chain management practices in order to ensure that they improve their speed and efficiency during disaster responses.

Supply chain management concepts such as agility, flexibility and responsiveness are relevant as they place an emphasis on customer focus (Aprile et al. 2005:25; Stevenson \& Spring 2007:685). It is suggested that if similar practices are adopted within the humanitarian supply chains of the relief operations, this would result in speedier and more efficient and effective response and action. Not many studies have focused on the practices of the humanitarian supply chains in southern Africa, which lag behind those in the commercial world. Yet the gap between the two has been identified as a contributing factor towards the effectiveness of their supply chain and may negatively impact on the suffering of the affected communities and the loss of lives.

A limitation of this study is that the focus was on providing an overview of how the UNWFP successfully responds to natural disaster operations in southern Africa. As a result it 
considers the viewpoint of the UNWFP only and not the viewpoint of other stakeholder. It is suggested therefore that a further study be conducted and that other key stakeholders such as the beneficiaries are included, so as to have a plurality of perspectives. This could further help in assessing how well the supply chain deployment is performing.

\section{Acknowledgements Competing interests}

The authors declare that they have no financial or personal relationships which may have inappropriately influenced them in writing this article.

\section{Authors' contributions}

N.K.N. collected and analysed the data. M.J.A.N. was the project leader, made conceptual contributions and finalised the article.

\section{References}

Aprile, D., Garavelli, A.C. \& Giannoccaro, I., 2005, 'Operations planning and flexibility in a supply chain', Journal of Production Planning and Control 16(1), 21-31. http:// dx.doi.org/10.1080/09537280412331313348

Balcik, B., Beamon, B.M., Krejci, C.C., Muramatsu, M.K. \& Ramirez, B., 2010, 'Coordination in humanitarian relief chains: Practices, challenges and opportunities', ordination in humanitarian relief chains: Practices, challenges and opportunities',
International Journal of Production Economics 126, 22-34. http://dx.doi. International Journal of Produc
org/10.1016/j.ijpe.2009.09.008

Baxter, P. \& Jack, S., 2008, 'Qualitative case study methodology: Study design and implementation for novice researchers', The Qualitative Report 13(4), 544-559.

Bean, W.L., Viljoen, N.M., Ittmann, W.H. \& Kekana, E., 2011, 'Disaster management and humanitarian logistics: A South African perspective', Journal of Transportation and Supply Chain Management 5(1), 39-51.

Camarinha-Matos, L.M. \& Afsarmanesh, H., 2004, 'The emerging discipline of collaborative networks', International Federation for Information Processing 149 3-16. http://dx.doi.org/10.1007/1-4020-8139-1_1

Chakravarty, A., 2010, 'A contingent plan for disaster response', International Journal of Production Economics 134(1), 3-15. http://dx.doi.org/10.1016/j.ijpe.2011.01.017

Chandra, C. \& Grabis, J., 2009, 'Configurable supply chain: Framework, methodology and application', International Journal of Manufacturing Technology and Management 17(1), 5-22. http://dx.doi.org/10.1504/IJMTM.2009.023776

Charles, A., Lauras, M. \& Van Wassenhove, L., 2010, 'A model to define and assess the agility of supply chains: Building on humanitarian experience', International Journal of Physical Distribution and Logistical Management 40(8), 722-741.

Chopra, S. \& Meindl, P., 2013, Supply chain management, strategy, planning and operations, 5th edn., Pearson, Prentice-Hall, Boston, MA.

Christopher, M. \& Towill, D., 2001, 'An integrated model for the design of agile supply chains', International Journal of Physical Distribution and Logistics Management 31(5), 235-246. http://dx.doi.org/10.1108/09600030110394914

Fritz Institute, 2010, Humanitarian logistics white paper, viewed 30 March 2015, from http://www.fritzinstitute.org/researchCenter.htm

Heizer, J. \& Render, B., 2014, Principles of operations management. Sustainability and supply chain management, 9th edn., Pearson, Boston, MA.

Herrmann, J., 2007, Disaster response planning \& preparedness: Phases of disaster: NYDIS manual for New York City religious leaders: Spiritual care and mental health for disaster response and recovery. New York Disaster Interfaith Services (affiliate of the National Disaster Interfaiths Network), New York, Services
pp. $11-14$.

Howden, M., 2009, 'How humanitarian logistics information systems can improve humanitarian supply chains: A view from the field', Proceedings from the 6th International ISCRAM Conference, Gothenburg, Sweden.

IFRC World Disasters Report, 2007, Focus on information in disasters, viewed 14 September 2013, from http://www.ifrc.org/publicat/wdr2005/

Ismail, H.S. \& Sharifi, H., 2006, 'A balanced approach to building agile supply chains', International Journal of Physical Distribution and Logistics Management 26(6), 431-444

Jangga, R., Ali, N.M., Ismail, M. \& Shari, N., 2015, 'Effect of environmental uncertainty and supply chain flexibility towards supply chain innovation: An exploratory study', Procedia Economics and Finance 31, 262-268. http://dx.doi.org/10.1016/ S2212-5671(15)01228-9

Kovacs, G. \& Spens, K.M., 2007, 'Humanitarian logistics in disaster relief operations', International Journal of Physical Distribution and Logistics Management 37(2), 99-114. http://dx.doi.org/10.1108/09600030710734820
Krajewski, L., Wei, J.C. \& Tang, L., 2005, 'Responding to schedule changes in build-to order supply chains', Journal of operations management 23, 452-469. http:// dx.doi.org/10.1016/j.jom.2004.10.006

Lukamba, M.T., 2010, 'Natural disasters in African countries: What can we learn about them?', The Journal of Trans-disciplinary Research in Southern Africa 6(2), 478-495. http://dx.doi.org/10.4102/td.v6i2.266

Malhotra, N.K., 2004, Marketing research: An applied orientation, 3rd edn., Prentice Hall, Englewood Cliffs, NJ.

Malhotra, N.K., 2007, Marketing research: An applied orientation, 5th edn., Prentice Hall, Englewood Cliffs, NJ.

McClintock, A., 2009, 'The logistics of humanitarian emergencies: Notes from the field', Journal of Contingencies and Crisis Management 17(4), 295-303. http:// dx.doi.org/10.1111/j.1468-5973.2009.00587.x

Minnich, D. \& Maier, F.H., 2005, Supply chain responsiveness and efficiency Complementing or contradicting each other? International University of Germany, Bruchsal, pp. 1-15.

Moe, L. \& Pathranarakul, P., 2006, 'An integrated approach to natural disaster management and its critical success factors', Disaster Prevention and Management 15(3), 396-413. http://dx.doi.org/10.1108/09653560610669882

Moeiny, E. \& Mokhlesi, J., 2004, 'Management of relief supply chain and humanitarian logistics through supply chain resilience', Master of Science, University of Boras.

Murray, S., 2005, 'How to deliver on the promises', Financial Times, 07 January, pp. 1-9.

Oloruntoba, R. \& Gray, R., 2006, 'Humanitarian aid in agile supply chains', Supply Chain Management an International Journal 11(2), 115-120. http://dx.doi. org/10.1108/13598540610652492

Pateman, H., Hughes, K. \& Cahoon, S., 2013, 'Humanizing humanitarian supply chains: A synthesis of key challenges', The Asian Journal of Shipping and Logistics 29(1) 81-102. http://dx.doi.org/10.1016/j.ajsl.2013.05.005

Perry, M. 2007, 'Natural disaster management planning: A study of logistics managers responding to the tsunami', International Journal of Physical Distribution \& Logistics Management 37(5), 409-433. http://dx.doi.org/10.1108/096000307 10758455

Pettit, S. \& Beresford, A., 2009, 'Critical success factors in the context of humanitarian aid supply chains', International Journal of Physical Distribution and Logistics Management 39(6), 450-468. http://dx.doi.org/10.1108/09600030910985811

Sheu, J., 2006, 'An emergency logistics distribution approach for quick response to urgent relief demand in disasters', Transportation Research Part E: Logistics and Transportation Review 43(6), 687-709. http://dx.doi.org/10.1016/j.tre.2006.04.004

Simchi-Levi, D., Kaminsky, P. \& Simchi-Levi, E., 2008, Designing and managing the supply chain: Concepts, strategies and case studies, 3rd International edn., McGraw Hill, Boston, MA.

Stevenson, M. \& Spring, M., 2007, 'Flexibility from a supply chain view perspective: Definition and review', International Journal of Operations and Production Management 27(7), 685-713. http://dx.doi.org/10.1108/01443570710756956

Talib, M.S.A. \& Hamid, A.B., 2014, 'Application of critical success factors in supply chain management', Faculty of Management University of Technology Malaysia 3(1), 22-33.

Tatham, P. \& Spens, K., 2011, 'Towards a humanitarian logistics knowledge management system', Disaster Prevention and Management 20(1), 6-26. http:// dx.doi.org/10.1108/09653561111111054

Tatham, P.H. \& Pettit, S.J., 2010, 'Transforming humanitarian logistics: The journey to supply network management', International Journal of Physical Distribution and Logistics Management 40(8), 609-622. http://dx.doi.org/10.1108/0960003 1011079283

Thomas, A. \& Kopczak, L. (2005), From logistics to supply chain management. The path forward in the humanitarian sector, Fritz Institute, viewed 04 March 2006, from http://www.fritzinstitute.org/PDFs/WhitePaper/FromLogisticsto.pdf

Tomasini, R.M. \& Van Wassenhove, L.N., 2004, 'Pan-American Health Organisations humanitarian supply management system: Depoliticization of the humanitarian supply chain by creating accountability', Journal of the Public Procurement $4(3)$ supply chain $437-449$.

Vonderembse, M.A., Uppal, M., Huang, S.H. \& Dismukes, J.P., 2006, 'Designing supply chains towards theory development', International Journal of Production Economics 100(2), 223-238. http://dx.doi.org/10.1016/j.ijpe.2004.11.014

United Nations (UN), 2009, Strengthening of the coordination of emergency humanitarian assistance of the United Nations, Report by the Secretary General to the General Assembly Economic and Social Council, viewed 14 September 2013, from www.reliefweb.int/rw/RWFILES2009.nsf/FilesByRWDocUnidFilename/ 2013, from www.reliefweb.int/rw/RWFILE2009.nsf/Fil

Wagner, C., Kawulich, B. \& Garner, M., 2012, Doing social research: A global context, McGraw-Hill Higher Education, London.

Wang, E.T.G., Tai, J.C.F. \& Wei, H., 2006, 'A virtual integration theory of improved supply chain performance', Journal of Management Information Systems 23(2), 41-46.

WFP, 2011, WFP policy on disaster risk reduction and management, building food security and resilience, viewed 20 March 2015, from http://www.wfp.org/ disaster-risk-reduction

Zhao, X., Xie, J. \& Zhang, W.F., 2002, 'The impact of information sharing and ordering co-ordination on supply chain performance', Supply Chain Management: An International Journal 7(1), 24-40. http://dx.doi.org/10.2753/MIS0742-1222230203 